\title{
Investigation of Farm Gate Cow Milk for Aflatoxin $M_{1}$
}

\author{
U.P.D. Pathirana, K.M.S. Wimalasiri ${ }^{1}$, K.F.S.T. Silva ${ }^{2}$ and S.P. Gunarathne ${ }^{3}$
}

\author{
Postgraduate Institute of Agriculture \\ University of Peradeniya \\ Peradeniya, Sri Lanka
}

\begin{abstract}
Importance of cow milk in human, especially in infant nutrition, is well known. Nevertheless, contamination of milk with aflatoxins is considered as a potential risk for human health. The aim of this study was to determine the levels of aflatoxin $M_{1}\left(A F M_{1}\right)$, metabolite of aflatoxin $B_{1}$ in raw cow milk in high milk producing areas in Sri Lanka. Aflatoxin $M_{1}$ levels were investigated by high performance liquid chromatography (HPLC) equipped with a fluorescence detector, monitoring at wave lengths $365 \mathrm{~nm}$ and $425 \mathrm{~nm}$ for excitation and emission, respectively. Eighty seven samples of raw milk were collected from randomly selected dairies in seven provinces in the country, and analyzed for $A F M_{1}$ using the Official Methods of Analysis of Association of Official Analytical Chemists (AOAC) International. The percentage recovery of $A F M_{1}$ was $85.2 \pm 4.03$ with respect to an artificially contaminated concentration of $48.6 \mathrm{ng} / \mathrm{L}$.
\end{abstract}

$A F M_{1}$ was detected in $33 \%$ of locally manufactured raw milk samples in concentrations ranging from $13.1 \mathrm{ng} / \mathrm{L}$ to $84.5 \mathrm{ng} / \mathrm{L}$ with a mean level of $40.2 \mathrm{ng} / \mathrm{L}$. Percentage of contaminated samples (9.2\%) exceeded the European Communities/Codex Alimentarius recommended limit of $50 \mathrm{ng} / \mathrm{L}$. None of the milk samples from Western, Uva \& Sothern provinces were contaminated at a detectable level of $A F M_{1}$. The results suggest a need to introduce safety measures for $A F M_{1}$ levels in liquid milk in local market under Prevention of Food Adulteration Act of Sri Lanka as well as to prescribe a limit of aflatoxin AFB ${ }_{1}$ level in dairy cattle feedstuffs in order to minimize the health hazard risk in Sri Lanka.

\section{INTRODUCTION}

Aflatoxins (AF) are a group of mycotoxins mainly produced by common fungi, namely Aspergillus flavus, A. parasiticus and A. nomius (JECFA, 2001). These fungi infect a wide range of agricultural commodities, especially cereals and oilseeds, both in the pre-harvest and post-harvest seasons (Galvano et al., 1996; Sarimehmetoglu et al., 2004). The occurrence of Aflatoxin $\mathrm{B} 1\left(\mathrm{AFB}_{1}\right)$ in feed material and their consumption has caused not only health hazards but also economic losses (Sarimehmetoglu et al., 2004). Aflatoxins, even in small amounts, are biologically active compounds that pose potential toxic, carcinogenic, teratogenic and/or mutagenic effects in human as well as in farm animals (Galvano et al., 1996) due to poor quality feeds. Aflatoxin B1 is usually regarded as a potent liver carcinogen

Department of Food Science \& Technology, Faculty of Agriculture, University of Peradeniya, Peradeniya 20400, Sri Lanka

2 Department of Animal Science, Faculty of Agriculture, University of Peradeniya, Peradeniya 20400, Sri Lanka

3 Department of Farm Animal Production \& Health, Faculty of Veterinary Medicine \& Animal Science,

University of Peradeniya, Peradeniya 20400, Sri Lanka 
for most mammalian species including humans (Zinedine et al., 2007). Aflatoxin $\mathrm{M}_{1}$ $\left(\mathrm{AFM}_{1}\right)$, the 4-hydroxylated metabolite of $\mathrm{AFB}_{1}$ known as "milk toxin" is less toxic compared to its parent material (Galvano et al., 1996; Galvano et al., 2005). Aflatoxin $M_{1}$ is formed in the liver by means of cytochrome P450-associated enzymes. It is known as a hepatic carcinogenic metabolite found in milk of lactating animals consuming $\mathrm{AFB}_{1}$ (JECFA, 2001; Manetta et al., 2005). International Agency for Research on Cancer (IARC) of World Health Organization defined $\mathrm{AFB}_{1}$ as primary and $\mathrm{AFM}_{1}$ as secondary group of carcinogenic compounds (Kaniou-Grigoriadou et al., 2005).

Martins and Martins (2004) reported that about 1-2\% of $\mathrm{AFB}_{1}$ in animal feed is transformed to $\mathrm{AFM}_{1}$ in milk with variations from animal to animal, from day to day and from one milking to the next. When the intake of $\mathrm{AFB}_{1}$ is stopped, the $\mathrm{AFM}_{1}$ concentration in the milk decreases to an undetectable level after 72 hours. Moreover, Galvano et al., (2005) reported that $0.3-6 \%$ of ingested $\mathrm{AFB}_{1}$ is available as $\mathrm{AFM}_{1}$ in milk. Many studies in the world reported the occurrence of $\mathrm{AFM}_{1}$ in dairy products and evidence of potential hazardous human exposure, as milk is a key source of nutrients for humans (Galvano et al., 1996). This is especially significant for infants and children, who are potentially more sensitive and have less variety in their diets. Seasonal trend in milk contamination was noted as there were occurrence of low levels of $\mathrm{AFM}_{1}$ during the spring and summer seasons. During these periods, the animals tend to consume more forage, roughage and pasture that are widely available than concentrate feed (Galvano et al., 1996; Sarimehmetoglu et al., 2004). Further, the climatic and storage conditions of the tropical and subtropical countries in the world are most favorable for the development and growth of aflatoxigenic fungi in food and feed stuffs. The geographical distribution and climatic variations within a country also can influence $\mathrm{AFM}_{1}$ occurrence and contamination levels in milk (Galvano et al., 1996). Sarimehmetoglu et al., (2004) reported that $\mathrm{AFM}_{1}$ is relatively stable in raw and processed milk products and is unaffected by pasteurization or processing into cheese. Even though $\mathrm{AFM}_{1}$ is more frequent in powdered milk than in fluid milk in Argentina, results indicate that the incidence is not much serious (López et al., 2003). Being a metabolite, $\mathrm{AFM}_{1}$ is stable under severe environmental conditions such as elevated temperatures and relative humidity. Human exposure to $\mathrm{AFM}_{1}$ is due to the consumption of contaminated milk and dairy products of which daily intake could be highly variable in the world. Infants represent the most exposed population due to their high consumption of dairy products either as bovine milk and related by-products in their diet or from breast milk where the mycotoxin can be excreted. JECFA (2001) reported that the intake of $\mathrm{AFM}_{1}$ from milk was $6.8 \mathrm{ng} /$ person/day for the European diet, $3.5 \mathrm{ng} /$ person/day for the Latin American diet, $12 \mathrm{ng} / \mathrm{person} /$ day for the Far Eastern diet, $0.7 \mathrm{ng} /$ person/day for the Middle Eastern diet and $0.1 \mathrm{ng} /$ person/day for the African diet. Thus, many countries have introduced regulations to control the levels of $\mathrm{AFB}_{1}$ in feed and have proposed Maximum Permissible Levels (MPL) for $\mathrm{AFM}_{1}$ in milk to reduce the risk.

Therefore, establishment of legal limit for $\mathrm{AFM}_{1}$ in Sri Lanka is very important to protect consumers from hazards that may occur due to $\mathrm{AFM}_{1}$ contamination. Currently, the legal limits are highly variable depending on the degree of the development and economic involvement of different countries (Galvano et al., 1996; Kaniou-Grigoriadou et al., 2005). According to the U.S. Food and Drug Administration, $\mathrm{AFM}_{1}$ in milk should not exceed 500 ng/L (US-FDA 2000; Manetta et al., 2005; Rastogi et al., 2004). Aflatoxin $\mathrm{M}_{1}$ level in milk has been set more restrictively to $50 \mathrm{ng} / \mathrm{L}$ by the European Union (EU) for adult consumption (EU Regulation 466/2001; Rastogi et al., 2004), while in baby-food products this level cannot be greater than $25 \mathrm{ng} / \mathrm{L}$ (EU Regulation 466/2001). 
There is little information about the occurrence of $\mathrm{AFM}_{1}$ in milk and milk products in Sri Lanka. Wimalasiri et al., (2005) found that there is high incidence of $\mathrm{AFM}_{1}$ in $82 \%$ of the local market samples of raw cattle milk and milk powder. Rostogi et al., (2004) reported that out of 87 milk and infant milk products in Indian market, almost $99 \%$ of the contaminated samples exceeded the European Community/Codex Alimentarius recommended limits, while 9\% samples exceeded the prescribed limit of US regulations.

The consumption of cow milk is highly popular among people in Sri Lanka. Further, these products are largely consumed by children including infants who are more sensitive to mycotoxins than adults (Galvano et al., 1996). Therefore, this study was carried out with the objective of investigating the presence of $\mathrm{AFM}_{1}$ in bovine milk samples from 29 selected dairies using High Performance Liquid Chromatograph (HPLC) equipped with a fluorescence detector.

\section{MATERIALS AND METHODS}

\section{Chemicals}

PrepSep ${ }^{\mathrm{TM}}$ SPE- $\mathrm{C}_{18}$ cartridges (particle size $40-45 \mu \mathrm{m}$, pore size $60^{\circ} \mathrm{A}$ and surface area 500 $\mathrm{m}^{2} \mathrm{~g}^{-1}$ ) were purchased from Fisher Scientific (Pittsburgh, USA). HPLC grade acetonitrile was purchased from BDH (Poole, England) and other chemicals and solvents of analytical grade were supplied by Merck (Darmstadt, Germany), Fluka (Buchs, Switzerland) and HIMEDIA (Mumbai, India). AFM 1 stock standard solution with a concentration of $486 \mu \mathrm{g} \mathrm{L}$ ${ }^{1}$ in acitonitrile was purchased from Biopure (Konrad Lorenz Strasse, Austria) and stored in the dark at $4{ }^{\circ} \mathrm{C}$. A working solution of $4860 \mathrm{ng} \mathrm{L}^{-1}$ was daily prepared in acetonitrile:water $(25: 75 \mathrm{v} / \mathrm{v})$ wrapped in aluminum foil and stored under the same conditions to prevent gradual break down of aflatoxins under UV light.

\section{Instrumentation}

Aflatoxin $\mathrm{M}_{1}$ was analyzed using an HPLC (SHIMUDZU, Kyoto, Japan) system consisting of a solvent delivery module (LC-10AT), column oven (CTO-10AVP/10ALVP) maintained at $35 \pm 1.0{ }^{\circ} \mathrm{C}$ and a fluorescence detector (RF-10AXL) in which excitation and emission wavelengths were set at $365 \mathrm{~nm}$ and $435 \mathrm{~nm}$, respectively. The eluate was passed through a Shim-pack CLC G-ODS $4 \mathrm{~mm}$ guard column followed by reversed phase $\mathrm{C}_{18}$ Shim-pack separating column $(150 \mathrm{~mm} \times 6.0 \mathrm{~mm})$ and data manipulation and chromatograms were obtained using SHIMUDZU chromatopac (C-R7A plus).

\section{Samples}

A total of 87 raw cow milk samples were collected from 29 dairies, representing seven provinces out of nine provinces in Sri Lanka, namely Western, Central, North-Central, Uva, Wayamba, Southern and Sabaragamuwa provinces. These provinces are particularly important due to their considerable contribution to the national milk production. Each sample of $200 \mathrm{~mL}$ volume, immediately after collection, was transported to the laboratory in ice boxes at temperatures about $4 \pm 2{ }^{\circ} \mathrm{C}$ and then stored at $-20{ }^{\circ} \mathrm{C}$ until analysis for $\mathrm{AFM}_{1}$. 


\section{Sample preparation}

The sample preparation was based on the method described by Manatta et al., (2005), with slight modifications. A sample of milk was homogenized and centrifuged at $1700 \mathrm{~g}$ for 20 $\mathrm{min}$. Then, $5 \mathrm{~mL}$ of the aqueous phase, diluted with an equal volume of deionized water, were purified on a SPE- $\mathrm{C}_{18}$ cartridge, after conditioning with acetonitrile $(5 \mathrm{~mL})$ followed by deionized water $(10 \mathrm{~mL})$. After applying the diluted samples and washing with water $(10$ $\mathrm{mL})$, followed by acetonitrile:water $(20: 80, \mathrm{v} / \mathrm{v})(20 \mathrm{~mL})$, fats were removed by washing with $n$-hexane $(2 \times 5 \mathrm{~mL})$. Aflatoxin $\mathrm{M}_{1}$ was eluted with dichloromethane:acetone $(95: 5, \mathrm{v} / \mathrm{v})$ $(6 \mathrm{~mL})$, the eluate was evaporated under a gentle stream of nitrogen and the residue dissolved in $1 \mathrm{ml}$ of acetonitrile. Then an aliquot $(20 \mu \mathrm{L})$ of the $\mathrm{AFM}_{1}$ extract was analyzed by HPLC.

\section{HPLC separation}

The mobile phase used for the analysis has been acetonitrile:water $(25: 75, \mathrm{v} / \mathrm{v})$. Isocratic elution of HPLC was performed at a flow rate of $1.0 \mathrm{~mL}$ min. Identification of $\mathrm{AFM}_{1}$ was based on its retention time with respect to the standard. Further identity confirmation was carried out by pre and post-injection of standard for each 10 batch sample set. The calibration curve, of peak area versus concentration, was linear as expected and data were fitted by the least-squares method. The line of regression was used to compute the amount of the analyte in sample extracts by extrapolation, using external standard method. Standard solutions for calibration curve of $\mathrm{AFM}_{1}$ were prepared by diluting stock solution with acetonitrile to obtain final concentrations in the range $30-486 \mathrm{ng} \mathrm{L}^{-1}$ (Fig. 1).

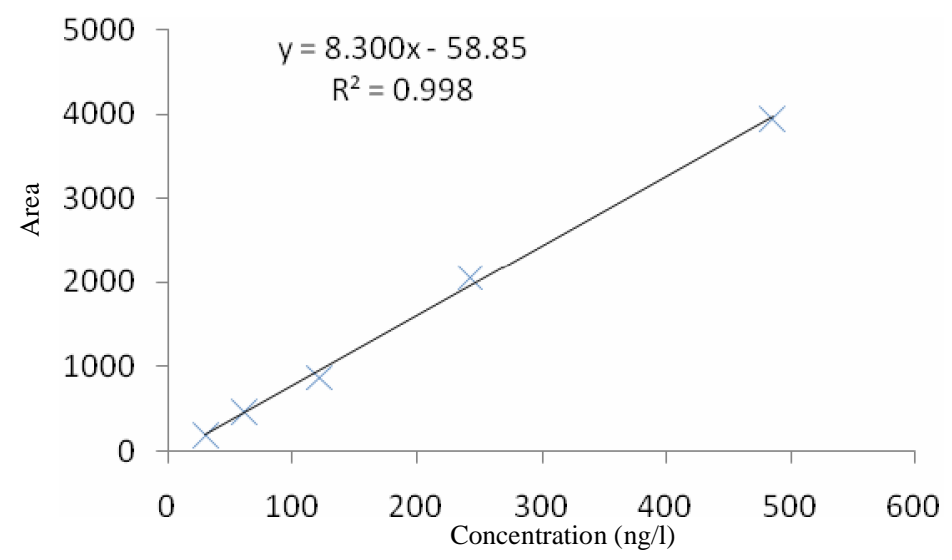

Fig. 1. Standard curve for $\mathrm{AFM}_{1}$ reference standards

\section{RESULTS AND DISCUSSION}

\section{Validation and Method Performance}

The chromatogram shown in Fig. 2A illustrates the efficiency of the proposed method: i.e. there are no interferences in the region where $\mathrm{AFM}_{1}$ is eluted. The retention time is about $13.0 \mathrm{~min}$. The lower detection limit or the minimum level at which the analyte can be 
reliably detected was found to be $10 \mathrm{ng} \mathrm{L}^{-1}$. Recovery percentage of $\mathrm{AFM}_{1}$ added to milk at a concentration of $48.6 \mathrm{ng} \mathrm{L}^{-1}$ was calculated to be $85.2 \% \pm 4.03$ by HPLC (Table 1)

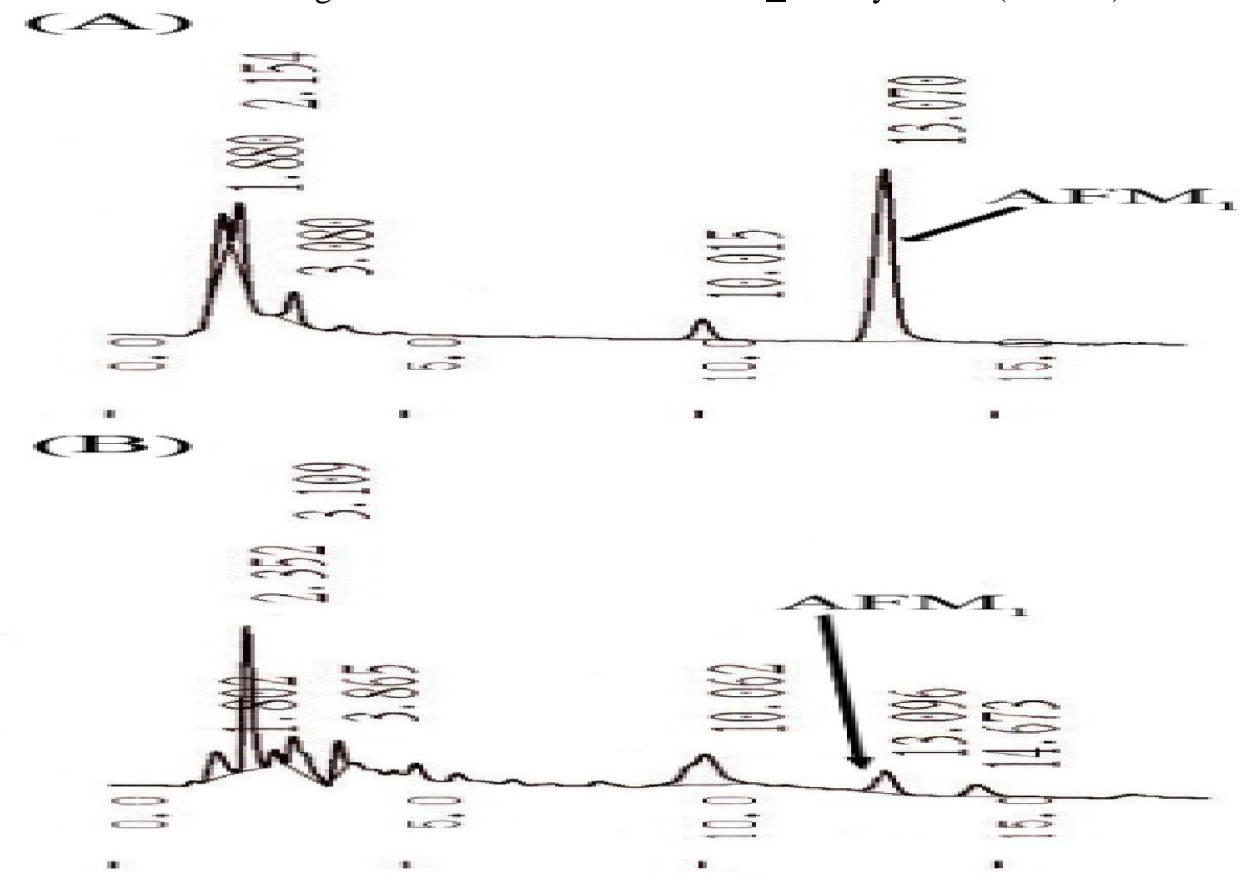

Fig. 2. Chromatograms of: (A) Reference standard (B) Sample matrix

Table 1. Recovery percentage of aflatoxin $M_{1}$ from artificially contaminated milk by HPLC

\begin{tabular}{lccccc}
\hline & $\begin{array}{c}\text { Before aflatoxin } \\
\mathbf{M}_{\mathbf{1}} \text { addition } \\
\text { (basal level ng/L) }\end{array}$ & $\begin{array}{c}\text { Aflatoxin } \\
\mathbf{M}_{\mathbf{1}} \text { added } \\
(\mathbf{n g} / \mathbf{L})\end{array}$ & $\begin{array}{c}\text { Expected } \\
\text { Aflatoxin } \mathbf{M}_{\mathbf{1}} \\
\text { level (ng/L) }\end{array}$ & $\begin{array}{c}\text { After aflatoxin } \mathbf{M}_{\mathbf{1}} \\
\text { addition (aflatoxin } \mathbf{M}_{\mathbf{1}}\end{array}$ & $\begin{array}{c}\text { Recovery } \\
\text { determined) }(\mathbf{( n g} / \mathbf{L})\end{array}$ \\
\hline Sample 1 & $38.1 \pm 3.4$ & 48.6 & $86.7 \pm 3.4$ & $72.4 \pm 7.1$ & 83.5 \\
Sample 2 & $35.6 \pm 2.7$ & 48.6 & $84.2 \pm 2.7$ & $69.3 \pm 8.3$ & 82.3 \\
Sample 3 & $40.4 \pm 7.8$ & 48.6 & $89 \pm 7.8$ & $79.9 \pm 5.8$ & 89.8 \\
Mean \pm SD & $38.0 \pm 2.4$ & 48.6 & $86.6 \pm 2.4$ & $73.9 \pm 5.4$ & $85.2 \pm 4.03$ \\
\hline
\end{tabular}

Milk samples spiked at different concentrations and processed as described in methodology

All analysis were performed in duplicate for each sample.

\section{Occurrence of $\mathrm{AFM}_{1}$ in milk}

The incidence of $\mathrm{AFM}_{1}$ contamination in milk was not very high, since only $33.3 \%$ of all samples were positive (Table 2). However, eight samples out of $87(9.2 \%)$ were over the permisssible level of $50 \mathrm{ng} \mathrm{L}^{-1}$, the regulatory limit of Europian Union (EU).

Zinedine et al., (2007) reported that the amount of $\mathrm{AFB}_{1}$ present in feed depends on temperature and moisture, under which conditions some moulds, such as A. flavus and A. parasiticus, can easily grow in feed. These moulds easily grow on feed having moisture contents between $13 \%$ and $18 \%$ and environmental moisture between $50 \%$ and $60 \%$. 
Table 2. Incidence and levels of aflatoxin $M_{1}$ in milk samples as determined by HPLC

\begin{tabular}{|c|c|c|c|c|c|c|c|c|}
\hline \multirow[t]{3}{*}{ Province } & \multirow{3}{*}{$\begin{array}{c}\text { Tested } \\
\text { (No.) }\end{array}$} & \multirow{3}{*}{$\begin{array}{c}\text { Positive (\%) } \\
\text { (No.) }\end{array}$} & \multicolumn{6}{|c|}{ Samples } \\
\hline & & & \multicolumn{4}{|c|}{ Frequency distribution No. (\%) } & \multicolumn{2}{|c|}{ Contamination } \\
\hline & & & $<10 \mathrm{ng} \mathrm{L}^{-1 \mathrm{a}}$ & $10-20 \mathrm{ng} \mathrm{L}^{-1}$ & $21-50 \mathrm{ng} \mathrm{L}^{-1}$ & $\geq 50 \mathrm{ng} \mathrm{L}^{-1}$ & Range & Average $^{c}$ \\
\hline Western & 9 & $0(0)$ & $9(10.3)$ & & & & & \\
\hline Central & 18 & $13(14.9)$ & $5(5.7)$ & $1(1.1)$ & $8(9.2)$ & $4(4.6)$ & & \\
\hline North Central & 15 & $5(5.7)$ & $10(11.5)$ & $3(3.4)$ & $2(2.3)$ & & & \\
\hline Uva & 9 & $0(0)$ & $9(10.3)$ & & & & & \\
\hline Wayamba & 15 & $7(8)$ & $8(9.2)$ & $1(1.1)$ & $3(3.4)$ & $3(3.4)$ & & \\
\hline Southern & 9 & $0(0)$ & $9(10.3)$ & & & & & \\
\hline Sabaragamuwa & 12 & $4(4.6)$ & $8(9.2)$ & & $3(3.4)$ & $1(1.1)$ & & \\
\hline Total & 87 & $29(33.3)$ & $58(66.7)$ & $5(5.7)$ & $16(18.4)$ & $8(9.2)$ & $13.1-84.5$ & 40.2 \\
\hline
\end{tabular}

Milk samples representing Uva, Western and Sothern provinces were negative for AFM1 probably due to usage of quality concentrate feeding materials or minimal/non concentrate feeding of dairy cattle. Other provinces such as Central, North Central, Wayamba \& Sabaragamuwa were positive for $\mathrm{AFM}_{1}$ and this may be due to poor feed quality with respect to $\mathrm{AFB}_{1}$ contamination. This confirms that the incidence of $\mathrm{AFM}_{1}$ contamination is often higher in countries where cows are fed with high amounts of compound concentrate feeds.

\section{CONCLUSIONS}

Considering these results, it could be concluded that $\mathrm{AFM}_{1}$ incidence in milk does not appear to be a serious public health problem in Sri Lanka at the moment. However, it is important to minimize exposure of milking animals to moldy feed contaminated with $\mathrm{AFB}_{1}$ and take necessary precautions to prevent fungal contaminations/growth particularly during the storage of feed. It is important to establish the maximum permissible levels for $\mathrm{AFM}_{1}$ in milk and milk products and $\mathrm{AFB}_{1}$ in foods and feeds based on the ALARA (As Low As Reasonably Achievable) principles, which do not exist under Food Act of Sri Lanka. Seasonal variation of $\mathrm{AFM}_{1}$ contamination in milk needs to be studied to assess the situation completely.

\section{ACKNOWLEDGMENT}

This research was funded by the National Science Foundation, Sri Lanka under the grant number RG/2006/AG/02. 


\section{REFERENCES}

AOAC. (1995). Natural toxins. Official Methods of Analysis. $\left(16^{\text {th }}\right.$ ed). Association of Official Analytical Chemists Inc, Virginia.

EU Regulation 466/2001 of 8 March 2001 (2001). Setting maximum levels for certain contaminants in foodstuff. Official J. of European Commission, L077, 11-12.

Galvano, F., Galofaro, V. and Galvano, G. (1996). Occurrence and stability of aflatoxin $\mathrm{M}_{1}$ in milk and milk products: A worldwide review. J. of Food Protec. 59, 1079-1090.

Galvano, F., Ritieni, A., Piva, G. and Pietri, A. (2005). Mycotoxin in the human food chain: The Mycotoxin Blue Book. (ed.) D. Diaz, Nottingham University Press, UK. pp. 187-224.

JECFA (2001). Fifty-sixth Meeting of the Joint FAO/WHO Expert Committee on Food Additives. Safety Evaluation of Certain Mycotoxins in Food. Food Additive Series, 47. World Health Organization, Geneva.

Kaniou-Grigoriadou, I., Eleftheriadou, A., Mouratidou, T. and Katikou, P. (2005). Determination of aflatoxin $\mathrm{M}_{1}$ in ewe's milk samples and the produced curd and Feta cheese. Food Contr. 16, 257-261.

López, C. E., Ramos, L.L., Ramadán, S.S. and Bulacio, L.C. (2003). Presence of aflatoxin $\mathrm{M}_{1}$ in milk for human consumption in Argentina. Food Contr. 14, 31-34.

Manetta, A.C., Giuseppe, L.D., Giammarco, M., Fusaro, I., Simonella, A., Gramenzi, A. and Formigoni, A. (2005). High-performance liquid chromatography with post-column derivatisation and fluorescence detection for sensitive determination of aflatoxin $\mathbf{M}_{1}$ in milk and cheese. J. Chromat. A. 1083, 219-222.

Martins, M. L. and Martins, H. M. (2004). Aflatoxin $M_{1}$ in yoghurts in Portugal. International J. of Food Microbiol. 91, 315-317.

Rastogi, S., Dwivedi, P.D., Khanna, S.K. and Das, M. (2004). Detection of aflatoxin $\mathrm{M}_{1}$ contamination in milk and infant milk products from Indian market by ELISA. Food Contr. 15, 287-290.

Sarimehmetoglu, B., Kuplulu, O. and Celik, T. H. (2004). Detection of aflatoxin $M_{1}$ in cheese samples by ELISA. Food Contr. 15, 45-49.

US-FDA (2000). Aflatoxin: Action levels for poisonous or deleterious substances in human food and animal feed. Industry Activities Staff Booklef, August 2000, CPG 527.400. http://www.fda.gov/ora/compliance ref/cpg/cpgfod/cpg527-400.html acess on:10 August, 2007.

Wimalasiri, K. M. S., Pathirana, U. P. D. \& Liyanage, P. K. (2005). Occurrence of aflatoxin $M_{1}$ in raw milk \& milk powder in the local market. Sri Lanka Association for the Advancement of Science, Proceedings of the $61^{\text {st }}$ Annual session,12-17 December, 2005. pp.1.

Zinedine, A., González-Osnaya, L., Soriano, J. M., Moltó, J. C., Idrissi, L. \& Mañes, J. (2007). Presence of aflatoxin $M_{1}$ in pasteurized milk from Morocco. Int. J. of Food Microbiol., 114, 25-29. 